\title{
ESPACIALIZAÇÃO DE INUNDAÇÕES EM GOIÂNIA (GO) (2004-2007)
}

\author{
SPATIALIZATION OF INUNDATIONS IN GOIÂNIA (GO) (2004-2007) \\ ESPACIALIZACIÓN DE LAS INUNDACIONES EN GOIANIA (GO) (2004-2007)
}

\author{
Kesia Rodrigues dos Santos - Universidade Federal de Goiás - Goiânia - Goiás - Brasil \\ k2r3s4@yahoo.com.br \\ Patrícia de Araújo Romão - Universidade Federal de Goiás - Goiânia - Goiás - Brasil \\ pat_iesa@yahoo.com.br
}

\section{Resumo}

0 presente trabalho foi realizado em Goiânia no estado de Goiás. Para alcançar o objetivo desse trabalho, que foi identificar os locais de ocorrência de inundações em Goiânia e espacializá-los, foram delimitadas as áreas de ocorrência de inundações na área urbana do município, por meio da compilação de informações contidas em artigos de jornais locais e de dados da Defesa Civil. As informações contidas nessas fontes de informação foram relevantes, não só para localização dos pontos de ocorrência de eventos como também para verificar quais são as áreas com recorrência de eventos e, portanto, mais problemáticas. Destacam-se bairros próximos ao rio Meia Ponte e ao Jardim Guanabara II nas margens do córrego Pedreira, como os que mais aparecem em manchetes. Já em relação à concentração de locais de ocorrência de inundações, a grande concentração de eventos ocorre na porção sul de Goiânia que se apresenta amplamente urbanizada, impermeabilizada e com a rede de drenagem modificada. Os demais pontos estão associados ao Anicuns, Meia Ponte e ao João Leite em menores proporções. Além desses locais, aparece o córrego Pedreira, o córrego Água Branca e alguns pontos considerados como alagamentos, por não estarem associados a cursos d'água.

Palavras-chave: inundações, ocorrências, mapeamento.

\section{Abstract}

This paper was accomplished in Goiânia the state of Goiás. To achieve the objective of this work, which was to identify the places of occurrence of inundation in Goiânia and spatialise them, were delineated areas of occurrence of inundation in urban area, through the collection of information contained in articles in local newspapers and data from the Civil Defense. The information contained in these sources were relevant not only for locations of occurrence of events and to check what are the areas with recurrent events, and therefore more problematic. Stand out neighborhoods close to the Meia Ponte river and Guanabara II garden on the banks of the stream Pedreira, such as those appearing in more headlines. In relation to the concentration of sites of occurrence of inundation the large concentration of events occurs in the southern portion of Goiania which appears largely urbanized, and sealed with the drainage changed. The remaining points are associated with Anicuns, Meia Ponte and João Leite in smaller proportions. In addition to these sites appear Pedreira stream, the stream Água Branca and some points regarded as floods, because they are not associated with watercourses.

Key words: inundation, occurrences, mapping.

\section{Resumén}

Este trabajo se llevó a cabo en Goiania en el estado de Goiás. Para alcanzar el objetivo de este trabajo, que consistía en identificar los lugares de ocurrencia de inundaciones en Goiania y spatialise ellos, se delimitaron las zonas de ocurrencia de inundaciones en el área urbana, a través de la recopilación de la información contenida en los artículos de periódicos locales y los datos de la Defensa Civil. La información contenida en estas fuentes son pertinentes no sólo para ubicación de los lugares de ocurrencia de los acontecimientos y para comprobar cuáles son las zonas con eventos recurrentes y por lo tanto más problemática. Se destacan los barrios cerca del río Meia Ponte y el jardín Guanabara Il a márgenes del arroyo Pedreira, como los que aparecen en más titulares. 
En función de la concentración de los sitios de ocurrencia de las inundaciones la gran concentración de eventos se produce en la porción sur de Goiania que aparece en gran parte urbanizada, y sellado con el drenaje cambiado. Los puntos restantes se asocian con Anicuns, Meia Ponte y João Leite en menores proporciones. Además de estos sitios aparecen el arroyo Pedreira, el arroyo Água Branca y algunos puntos considerados como "alagamentos", debido a que no están asociados a cursos de agua.

Palabras clave: inundaciones, eventos, mapa.

Introdução

As inundações em áreas urbanas são fenômenos condicionados por fatores naturais, que podem ser agravados em razão de fatores antrópicos. Tucci (1999) apresenta tal afirmação e assinala também que processos naturais e antrópicos podem atuar de forma integrada nas inundações em áreas urbanas. As inundações podem ser classificadas em ribeirinhas, urbanas e localizadas. Os três tipos podem ainda estar associados em um mesmo local.

Segundo a classificação de Tucci (1999), as inundações em áreas ribeirinhas são aquelas que fazem parte da dinâmica natural de um canal de drenagem. Neste caso, a ocupação não é a causa da inundação, e o acidente ocorre porque áreas naturalmente inundáveis foram ocupadas. Esse mesmo autor ressalta ainda em outra obra (Tucci, 2003b) que quando a precipitação é intensa e o solo não tem capacidade de infiltrar, grande parte do volume escoa para o sistema de drenagem, superando sua capacidade natural de escoamento. O excesso do volume que não é drenado ocupa a várzea, inundando de acordo com a topografia das áreas próximas aos rios. Estes eventos ocorrem de forma aleatória por causa dos processos climáticos locais e regionais.

No que se refere à inundação causada pela urbanização ou pela drenagem urbana, ela pode ser entendida com base na análise da ocupação e, consequentemente, da impermeabilização. Na medida em que a população impermeabiliza o solo e acelera o escoamento por meio de condutos e canais, a quantidade de água que chega ao mesmo tempo no sistema de drenagem aumenta, produzindo inundações mais frequentes do que as que existiam quando a superfície era mais permeável e o escoamento se dava pelo ravinamento natural (Tucci, 2003b). Nesses casos, embora a inundação seja um fenômeno natural, ela pode também ocorrer em áreas nunca atingidas pelas águas ou não suscetíveis à inundação, mas que se tornaram sujeitas à sua ocorrência em razão da ação antrópica (Souza, 1996). 
Existem ainda as inundações localizadas que podem ser provocadas por estrangulamento da seção do rio, remanso, erros de execução e projeto de drenagem de rodovias e avenidas, entre outros (Tucci, 1999). Entre esses fatores, podem-se destacar o estrangulamento da seção por pontes e bueiros, a construção de aterros no leito do rio e o assoreamento da drenagem por sedimentos e/ou lixo. Além dos estrangulamentos, o aumento de sedimentos e material sólido reduz a capacidade de escoamento dos rios. Assim, o assoreamento e as obras de intervenção são fatores potencializadores das inundações.

Quanto aos problemas resultantes da inundação, pode-se afirmar que eles dependem do grau de ocupação da várzea pela população, no caso da inundação ribeirinha, e da impermeabilização e canalização da rede de drenagem, no caso das inundações urbanas. As inundações ribeirinhas têm sido registradas junto com a história do desenvolvimento humano. As inundações causadas pela urbanização têm sido mais frequentes a partir do século XX, com o aumento significativo da urbanização das cidades e a tendência dos engenheiros em drenar o mais rápido possível o escoamento pluvial das áreas urbanizadas (Tucci, 2003b). Esse processo necessita de diferentes ações preventivas de planejamento urbano e ambiental, para minimizar os impactos e buscar o desejável desenvolvimento sustentável (Tucci, 2003a). A ocupação imprópria das áreas urbanas pode ser evitada por meio do planejamento do uso dos solos das várzeas, que deve ser regulamentado pelo Plano Diretor Urbano das cidades (Tucci, 2003b).

Existem em Goiânia diversos acidentes relacionados à inundação. Este artigo teve por objetivo buscar e organizar os dados existentes sobre as principais ocorrências desse fenômeno e identificar a distribuição espacial dos eventos na cidade. O levantamento das informações sobre distribuição espacial das inundações teve como fontes jornais e registros da Defesa Civil e do Corpo de Bombeiros. Com os dados obtidos, cada ponto de ocorrência de inundação foi localizado por suas coordenadas a partir da identificação dos endereços fornecidos e/ou dos pontos de referência. Na definição das coordenadas de alguns pontos descritos, a precisão relacionada à escala adotada não foi alcançada por causa da falta de detalhamento da descrição relatada nos jornais, o que fez com que esses pontos fossem somente descritos.

Como ferramenta para a obtenção dos pontos $x$ e y, utilizou-se o software Siggo v2 fornecido pela prefeitura de Goiânia (Comdata, 2007). A 
espacialização dos pontos foi realizada utilizando o software Spring 5.1.3 e, posteriormente, finalizada com o software ArcGis 3.2.

\section{Os registros de inundação em Goiânia}

O levantamento dos dados sobre os acidentes relacionados à dinâmica fluvial em Goiânia com ênfase na inundação teve início com o inventário de tais acidentes em notícias de jornais. Os dados compilados de jornais locais foram importantes por apresentarem a data, o local e a ocorrência relacionada à dinâmica fluvial ou, em alguns casos, pluvial (alagamentos).

Após pesquisa nos principais jornais impressos de Goiânia chegou-se a uma lista de locais que inundavam e das consequências desse fenômeno nesses locais. Com esses dados, somados à frequência em que ocorriam, e a data em que ocorreram, chegou-se à Tabela 1, que mostra as ocorrências de inundações identificadas a partir de notícias veiculadas em jornais locais de 2004 a 2007. Os dados apresentados na Tabela 1 mostraram 24 locais de ocorrência de inundações em Goiânia.

Cabe ressaltar que as informações contidas nas notícias de jornais foram relevantes principalmente para se ter ideia inicial de áreas problemáticas. Isso porque essas áreas apareceram em diversas manchetes. Entre elas, destacam-se bairros próximos ao rio Meia Ponte e às margens do córrego Pedreira, localizado este último no Jardim Guanabara II. O rio Meia Ponte apresenta larga planície de inundação, grande volume de água e outras características que o tornam propenso à ocorrência de inundações no local. Em contrapartida, o córrego Pedreira, que é tributário do ribeirão João Leite, que por sua vez é tributário do rio Meia Ponte, apresenta estreita ou quase inexistente planície de inundação e também apresenta ocorrência de inundações. As razões disso são as características do meio físico que favorecem o escoamento e a concentração do fluxo na bacia, além da ocupação que favorece a impermeabilização de parte da bacia.

Os dados sobre a ocorrência de inundações que foram tabulados pela defesa civil mostram que os eventos são recorrentes dentro de um mesmo ano e repetidos anualmente. A frequência de ocorrências de eventos a cada ano no córrego Pedreira iguala-se à de bacias hidrográficas com maior extensão espacial e ocupação. O mesmo pode ser dito a propósito de rios como o Meia Ponte e o João Leite, que apresentam larga planície de inundação, com bairros inteiros instalados nessa porção do relevo. 
Tabela 1 - Ocorrência de eventos relacionados à dinâmica fluvial em Goiânia (2004-2007).

\begin{tabular}{|c|c|c|c|c|}
\hline Localização & $\begin{array}{l}\text { Frequência } \\
\text { a cada ano }\end{array}$ & Ocorrência & $\begin{array}{c}\text { Data do } \\
\text { evento mais } \\
\text { expressivo }\end{array}$ & Consequências \\
\hline $\begin{array}{l}\text { Rio Meia Ponte (Setor Coronel } \\
\text { Cosme, Urias Magalhães, Vila } \\
\text { Monticelli, Vila Roriz e Setor Jaó) }\end{array}$ & 3 & Inundação & $23 / 2 / 2004$ & $\begin{array}{l}\text { Moradores levantam } \\
\text { os móveis para evitar } \\
\text { perdas maiores. }\end{array}$ \\
\hline Vila Montecelli (Rio Meia Ponte) & 3 & Inundação & $19 / 3 / 2004$ & $\begin{array}{l}\text { Inundação de casas, o } \\
\text { que trouxe prejuízos, } \\
\text { além de muita lama, lixo } \\
\text { e animais. }\end{array}$ \\
\hline $\begin{array}{l}\text { Rio Meia Ponte (vilas Roriz e } \\
\text { Monticelli, Setor Coronel Cosme } \\
\text { e Jardim Novo Mundo) }\end{array}$ & 3 & Inundação & $10 / 3 / 2004$ & $\begin{array}{l}\text { Moradias subnormais } \\
\text { foram afetadas. Danos } \\
\text { materiais } \\
\text { e desespero das famílias. }\end{array}$ \\
\hline Região Central & 1 & Alagamento & $12 / 10 / 2004$ & $\begin{array}{l}\text { Enxurrada alcançou } \\
40 \mathrm{~cm} \text {, invadiu lojas e } \\
\text { dificultou travessia. }\end{array}$ \\
\hline $\begin{array}{l}\text { Vila Santa Rita e Recanto dos } \\
\text { Bosques }\end{array}$ & 1 & Alagamento & $12 / 10 / 2004$ & Casas foram alagadas \\
\hline $\begin{array}{l}\text { Vila Coronel Cosme (à margem } \\
\text { do Meia Ponte) }\end{array}$ & 1 & Área de risco & $12 / 10 / 2004$ & $\begin{array}{l}\text { Quintal que faz divisa } \\
\text { com o Rio foi aterrado } \\
\text { com entulho }\end{array}$ \\
\hline Conjunto Caiçara (BR- 153) & 1 & Alagamento & $10 / 3 / 2005$ & $\begin{array}{l}\text { Estragos na AABB, } \\
\text { Platinum e CT do Vila } \\
\text { Nova }\end{array}$ \\
\hline $\begin{array}{l}\text { Parque Amazônia (Avenida Feira } \\
\text { de Santana) }\end{array}$ & 1 & $\begin{array}{l}\text { Bueiro } \\
\text { transbordou }\end{array}$ & $29 / 11 / 2005$ & $\begin{array}{l}\text { Engarrafamento de } \\
\text { ônibus e carros de } \\
\text { passeio }\end{array}$ \\
\hline $\begin{array}{l}\text { Avenida Rio Verde (entre Goiânia } \\
\text { e Aparecida) }\end{array}$ & 1 & Alagamento & $29 / 11 / 2005$ & $\begin{array}{l}\text { Carros que arriscaram } \\
\text { a travessia ficaram } \\
\text { estragados. }\end{array}$ \\
\hline $\begin{array}{l}\text { Jardim da Luz próximo ao Buriti } \\
\text { Shopping - córrego próximo à } \\
\text { Avenida Maria Cardoso. }\end{array}$ & 1 & $\begin{array}{l}\text { Enxurrada } \\
\text { próximo ao } \\
\text { córrego }\end{array}$ & $29 / 11 / 2005$ & $\begin{array}{l}\text { Carro foi levado pela } \\
\text { enxurrada e caiu no } \\
\text { córrego; duas pessoas } \\
\text { tiveram ferimentos leves. }\end{array}$ \\
\hline $\begin{array}{l}\text { Vila Alzira (Avenida das } \\
\text { Mangueiras) }\end{array}$ & 1 & $\begin{array}{l}\text { Ponte caiu } \\
\text { após chuva }\end{array}$ & $29 / 11 / 2005$ & 0 tráfego foi desviado \\
\hline $\begin{array}{l}\text { Bairro Goyá (região oeste de } \\
\text { Goiânia) - a Rua da Alegria }\end{array}$ & 1 & Alagamento & $29 / 11 / 2005$ & $\begin{array}{l}\text { A ponte que passa sobre } \\
\text { a rua foi interditada }\end{array}$ \\
\hline $\begin{array}{l}\text { Vila Roriz (Rio Meia Ponte, na } \\
\text { Rua Cloves Roberto Espelin) }\end{array}$ & 4 & Inundação & $10 / 12 / 2005$ & $\begin{array}{l}\text { Destruição de móveis } \\
\text { e bens (carros), } \\
\text { desconforto, revolta e } \\
\text { medo. }\end{array}$ \\
\hline $\begin{array}{l}\text { Vila Maria Rosa, região nordeste } \\
\text { de Goiânia (Ribeirão João Leite) }\end{array}$ & 2 & $\begin{array}{l}\text { Alagamento } \\
\text { (inundação) }\end{array}$ & $9 / 4 / 2006$ & Casas alagadas \\
\hline
\end{tabular}




\begin{tabular}{|c|c|c|c|c|}
\hline Localização & $\begin{array}{l}\text { Frequência } \\
\text { a cada ano }\end{array}$ & Ocorrência & $\begin{array}{l}\text { Data do } \\
\text { evento mais } \\
\text { expressivo }\end{array}$ & Consequências \\
\hline $\begin{array}{l}\text { Bairro Emílio Póvoa (Ribeirão } \\
\text { João Leite) }\end{array}$ & 1 & $\begin{array}{l}\text { Risco de } \\
\text { desabamento. }\end{array}$ & $9 / 4 / 2006$ & $\begin{array}{l}\text { Alguns moradores } \\
\text { abandonaram suas } \\
\text { casas }\end{array}$ \\
\hline $\begin{array}{l}\text { Jardim Guanabara II (córrego } \\
\text { Pedreira) }\end{array}$ & 3 & $\begin{array}{l}\text { Inundação }(1,5 \\
\text { metro) }\end{array}$ & $29 / 12 / 2006$ & $\begin{array}{l}50 \text { casas atingidas, } \\
\text { objetos foram perdidos } \\
\text { e transtorno causado } \\
\text { pelo lixo. }\end{array}$ \\
\hline $\begin{array}{l}\text { Jardim Goiás, na área conhecida } \\
\text { como Vila Lobó }\end{array}$ & 1 & Alagamento & 23/9/2006 & $\begin{array}{l}\text { Água das enxurradas } \\
\text { invadiu casas e causou } \\
\text { prejuízos. }\end{array}$ \\
\hline Celina Park (córrego Macambira) & 1 & $\begin{array}{l}\text { Alagamento, } \\
\text { inundação e } \\
\text { erosão fluvial }\end{array}$ & $5 / 10 / 2006$ & $\begin{array}{l}\text { Riscos e prejuízos à } \\
\text { população }\end{array}$ \\
\hline $\begin{array}{l}\text { Jardim Goiás, na área conhecida } \\
\text { como Vila Lobó }\end{array}$ & 1 & Alagamento & $4 / 10 / 2006$ & $\begin{array}{l}\text { Água das enxurradas } \\
\text { arrastou árvores, muros } \\
\text { e invadiu casas. }\end{array}$ \\
\hline $\begin{array}{l}\text { Vila Monticelli (moradias em } \\
\text { áreas subnormais) }\end{array}$ & 1 & Alagamento & $7 / 12 / 2006$ & $\begin{array}{l}\text { Enxurrada e esgoto } \\
\text { deixam moradores } \\
\text { ilhados }\end{array}$ \\
\hline $\begin{array}{l}\text { Recanto do Bosque (moradias } \\
\text { subnormais) }\end{array}$ & 1 & Alagamento & $7 / 12 / 2006$ & $\begin{array}{l}\text { Área fica alagada em } \\
\text { todo período chuvoso }\end{array}$ \\
\hline $\begin{array}{l}\text { Rua C-6 com a Avenida C-4, } \\
\text { no Jardim América (Córrego } \\
\text { Cascavel). }\end{array}$ & 2 & $\begin{array}{l}\text { Inundação / } \\
\text { desabamento }\end{array}$ & $5 / 1 / 2007$ & $\begin{array}{l}\text { Elevação do nível da } \\
\text { água e desabamento. }\end{array}$ \\
\hline
\end{tabular}

Fonte: Dados compilados de notícias de jornais - 2004 a 2007.

A Tabela 2 mostra os dados referentes às famílias que vivem em áreas de risco, disponibilizados pela Defesa Civil. Os dados apresentados pretendem destacar a localização das ocorrências de acidentes, sua caracterização e a quantidade de pessoas expostas a esse fenômeno. Com base nessa tabela, pode-se afirmar que o número de locais que apresentaram problemas relacionados à dinâmica pluvial foi menor do que o obtido na Tabela 1, sendo aqui delimitados 16 locais considerados áreas de risco.

A análise comparativa das duas tabelas trouxe informações que foram importantes para definir locais que, por aparecerem nas duas tabelas, são considerados casos problemáticos ou críticos. Além disso, nas características apresentadas pela Defesa Civil e pelas reportagens, essa análise possibilitou a identificação do tipo de evento e sua adequação à nomenclatura.

Como pode ser observado na Tabela 2, grande parte dos acidentes estão relacionados à dinâmica fluvial, seguidos dos acidentes relaciona- 
dos à dinâmica pluvial. As inundações e erosões fluviais representam nessa tabela a predominância de acidentes, indicando que foram ocupadas as áreas de preservação permanente próximas aos cursos d’água.

Tabela 2 - Goiânia: riscos de desastres relacionados com o incremento de precipitações hídricas e com as inundações.

\begin{tabular}{|c|c|c|c|c|c|c|c|}
\hline \multirow[b]{2}{*}{ Setor } & \multirow[b]{2}{*}{ Delimitação } & \multirow{2}{*}{$\begin{array}{l}\text { Ameaças e } \\
\text { Riscos }\end{array}$} & \multirow{2}{*}{$\begin{array}{c}\text { Grau } \\
\text { de } \\
\text { Risco }\end{array}$} & \multirow{2}{*}{$\begin{array}{c}N . \text { de } \\
\text { moradias }\end{array}$} & \multicolumn{2}{|c|}{ N. de pessoas } & \multirow[b]{2}{*}{ Observações } \\
\hline & & & & & Adultos & Crianças & \\
\hline $\begin{array}{l}\text { Vila Cel. } \\
\text { Cosme II }\end{array}$ & $\begin{array}{l}\text { Entre a rua da } \\
\text { Paz (abaixo } \\
\text { da via férrea) } \\
\text { e o Rio Meia } \\
\text { Ponte. }\end{array}$ & $\begin{array}{l}\text { Inundações ou } \\
\text { alagamentos. }\end{array}$ & $\begin{array}{l}\text { Alto } \\
\text { Médio } \\
\text { Baixo }\end{array}$ & $\begin{array}{c}7 \\
72 \\
15\end{array}$ & 254 & 137 & $\begin{array}{l}\text { Em razão da topografia } \\
\text { acidentada e de as } \\
\text { moradias serem } \\
\text { construídas de maneira } \\
\text { precária, há o risco } \\
\text { de desabamento e } \\
\text { inundação em virtude } \\
\text { de elevação do rio. }\end{array}$ \\
\hline $\begin{array}{l}\text { Jardim das } \\
\text { Aroeiras }\end{array}$ & $\begin{array}{l}\text { Av. das } \\
\text { Aroeiras } \\
\text { (Invasão do } \\
\text { Buracão) }\end{array}$ & $\begin{array}{l}\text { Enxurradas, } \\
\text { Inundações } \\
\text { Bruscas, } \\
\text { Escorrega- } \\
\text { mentos ou } \\
\text { Deslizamentos }\end{array}$ & $\begin{array}{l}\text { Alto } \\
\text { Médio }\end{array}$ & $\begin{array}{l}5 \\
4\end{array}$ & 19 & 18 & $\begin{array}{l}\text { Moradias construídas } \\
\text { em áreas de depressão } \\
\text { (buracão), sujeitas às } \\
\text { ações das enxurradas, } \\
\text { podendo causar } \\
\text { desabamentos das } \\
\text { moradias. }\end{array}$ \\
\hline $\begin{array}{l}\text { Vila } \\
\text { Fernandes }\end{array}$ & $\begin{array}{l}\text { Rua 30-A, } \\
\text { Od 1, } 2 \text { e } 3 \\
\text { Lt do } 1 \text { ao } 8, \\
10 \text { e } 12 \text { próx. } \\
\text { ao Ribeirão } \\
\text { Anicuns. }\end{array}$ & $\begin{array}{l}\text { Inundações } \\
\text { Graduais e } \\
\text { Alagamentos }\end{array}$ & Baixo & 12 & 35 & 6 & $\begin{array}{l}\text { Moradias construídas } \\
\text { na planície de } \\
\text { inundação do ribeirão. } \\
\text { Foi realizado o } \\
\text { aterramento dos lotes } \\
\text { das residências, o que } \\
\text { possibilitou o aumento } \\
\text { do nível das moradias. }\end{array}$ \\
\hline $\begin{array}{l}\text { Jardim } \\
\text { Guanabara II }\end{array}$ & $\begin{array}{l}\text { Rua Gb 26 } \\
\text { (margens } \\
\text { do Ribeirão } \\
\text { Pedreira) e } \\
\text { Rua GB } 27 \\
\text { (1 }{ }^{\mathrm{a}} \text { quadra } \\
\text { acima). }\end{array}$ & $\begin{array}{l}\text { Enxurradas ou } \\
\text { Inundações } \\
\text { Bruscas ou } \\
\text { Graduais }\end{array}$ & Médio & 69 & 201 & 137 & $\begin{array}{l}\text { Moradias afetadas } \\
\text { por enxurradas por } \\
\text { causa de rede pluvial } \\
\text { insuficiente, tendo risco } \\
\text { de alagamento em } \\
\text { razão da proximidade } \\
\text { do ribeirão, bem como } \\
\text { de desabamento das } \\
\text { edificações, que são de } \\
\text { alvenaria com estrutura } \\
\text { instável. }\end{array}$ \\
\hline Vila Isabel & $\begin{array}{l}\text { Lado direito } \\
\text { na baixada da } \\
2^{a} \text { radial no } \\
\text { SPL (sentido } \\
\text { Rendeção- } \\
\text { Terminal). }\end{array}$ & Erosão Fluvial & Baixo & 8 & 15 & 8 & $\begin{array}{l}\text { Desbarrancamento } \\
\text { causado por } \\
\text { precipitações hídricas, } \\
\text { podendo atingir } \\
\text { moradias próximas } \\
\text { às margens. Existe o } \\
\text { risco de desabamento } \\
\text { das moradias em } \\
\text { razão da deficiência } \\
\text { de sustentação das } \\
\text { moradias. }\end{array}$ \\
\hline
\end{tabular}




\begin{tabular}{|c|c|c|c|c|c|c|c|}
\hline \multirow[b]{2}{*}{ Setor } & \multirow[b]{2}{*}{ Delimitação } & \multirow{2}{*}{$\begin{array}{l}\text { Ameaças e } \\
\text { Riscos }\end{array}$} & \multirow{2}{*}{$\begin{array}{c}\text { Grau } \\
\text { de } \\
\text { Risco }\end{array}$} & \multirow{2}{*}{$\begin{array}{c}\text { N. de } \\
\text { moradias }\end{array}$} & \multicolumn{2}{|c|}{ N. de pessoas } & \multirow[b]{2}{*}{ Observações } \\
\hline & & & & & Adultos & Crianças & \\
\hline $\begin{array}{l}\text { Urias } \\
\text { Magalhães }\end{array}$ & $\begin{array}{l}\text { Av. Pampulha } \\
\text { - Chác. n. } 2,4 \text {, } \\
5 \text { e } 6 .\end{array}$ & $\begin{array}{l}\text { Enchentes ou } \\
\text { Inundações } \\
\text { Graduais }\end{array}$ & Médio & 4 & 6 & 8 & $\begin{array}{l}\text { Inundações verificadas } \\
\text { a partir de } 02 / 02 \text {. Foi } \\
\text { elevado o nível das } \\
\text { moradias. }\end{array}$ \\
\hline $\begin{array}{l}\text { V. N. Sra. } \\
\text { Aparecida }\end{array}$ & $\begin{array}{l}\text { Rua } 1 \text { - Chác. } \\
\text { n. 1, } 2 \text { e } 3\end{array}$ & $\begin{array}{l}\text { Inundações } \\
\text { Graduais }\end{array}$ & Médio & 3 & 19 & 5 & $\begin{array}{l}\text { Inundações verificadas } \\
\text { a partir de } 2 / 2 \text {. Foi } \\
\text { elevado o nível das } \\
\text { moradias. }\end{array}$ \\
\hline Emílio Povoa & $\begin{array}{l}\text { Lado dir. da } \\
\text { Al. Botafogo } \\
\text { entre a Av. } \\
1 \mathrm{~V} \text {. Nova } \\
\text { e R. Dr. } \\
\text { Constantino } \\
\text { Gomes no } \\
\text { Crimeia Leste. }\end{array}$ & $\begin{array}{l}\text { Enxurradas ou } \\
\text { Inundações } \\
\text { Bruscas e } \\
\text { Escorrega- } \\
\text { mentos ou } \\
\text { Deslizamentos }\end{array}$ & $\begin{array}{l}\text { Alto } \\
\text { Médio } \\
\text { Total }\end{array}$ & $\begin{array}{c}98 \\
70 \\
168\end{array}$ & 392 & 191 & $\begin{array}{l}\text { Em razão da topografia } \\
\text { acidentada e das } \\
\text { moradias construídas } \\
\text { de maneira precária, há } \\
\text { o risco de desabamento } \\
\text { em virtude de } \\
\text { deslizamentos, } \\
\text { escorregamentos e } \\
\text { enxurradas. }\end{array}$ \\
\hline $\begin{array}{l}\text { Água } \\
\text { Branca }\end{array}$ & $\begin{array}{l}\text { Nascente do } \\
\text { Córrego Água } \\
\text { Branca }\end{array}$ & $\begin{array}{l}\text { Enxurradas ou } \\
\text { Inundações } \\
\text { Bruscas e } \\
\text { Escorrega- } \\
\text { mentos ou } \\
\text { Deslizamentos }\end{array}$ & Alto & 5 & 4 & 1 & $\begin{array}{l}\text { Inundações verificadas } \\
\text { nas moradias, em } \\
\text { virtude de localizarem- } \\
\text { se às margens de um } \\
\text { córrego, havendo o } \\
\text { risco de deslizamento, } \\
\text { pois a estrutura de } \\
\text { sustentação, que é de } \\
\text { alvenaria, é instável. }\end{array}$ \\
\hline $\begin{array}{l}\text { Vila } \\
\text { Monticelli }\end{array}$ & $\begin{array}{l}\text { Fundo da } \\
\text { Saneago, } \\
\text { próximo ao } \\
\text { ribeirão Meia } \\
\text { Ponte. }\end{array}$ & $\begin{array}{l}\text { Inundações } \\
\text { Bruscas e } \\
\text { Escorrega- } \\
\text { mentos ou } \\
\text { Deslizamentos }\end{array}$ & Alto & 50 & 124 & 77 & $\begin{array}{l}\text { Inundações } \\
\text { provenientes da } \\
\text { elevação das águas } \\
\text { do rio Meia Ponte e } \\
\text { deslizamento por causa } \\
\text { do terreno acidentado. }\end{array}$ \\
\hline $\begin{array}{l}\text { Jardim } \\
\text { América }\end{array}$ & $\begin{array}{l}\text { Av. Chile Od. } \\
\text { 406A, Lt. } 1 \text { e } \\
\text { Lt. } 2 .\end{array}$ & $\begin{array}{l}\text { Enxurradas ou } \\
\text { Inundações } \\
\text { Bruscas }\end{array}$ & Alto & 2 & 3 & 7 & $\begin{array}{l}\text { Moradias construídas } \\
\text { às margens do córrego } \\
\text { Cascavel. }\end{array}$ \\
\hline $\begin{array}{l}\text { Vila Santa } \\
\text { Efigênia }\end{array}$ & $\begin{array}{l}\text { Margens do } \\
\text { córrego Vaca } \\
\text { Brava (em } \\
\text { frente à Santa } \\
\text { Casa) }\end{array}$ & Erosão Fluvial & Médio & 4 & 9 & 3 & $\begin{array}{l}\text { Desbarrancamento } \\
\text { causado por } \\
\text { precipitações hídricas, } \\
\text { podendo atingir } \\
\text { moradias próximas às } \\
\text { margens (moradias } \\
\text { para hospedagens). }\end{array}$ \\
\hline $\begin{array}{l}\text { Vila São } \\
\text { Paulo }\end{array}$ & $\begin{array}{l}\text { Rua Padre } \\
\text { Antão Chác. } \\
\text { C-3. Rua } 4 \text { e } 5 \\
\text { Od 1415,17 e } \\
18 \text { próximos } \\
\text { ao Ribeirão } \\
\text { Anicuns. }\end{array}$ & $\begin{array}{l}\text { Enxurradas e } \\
\text { Alagamentos }\end{array}$ & Baixo & 40 & 121 & 42 & $\begin{array}{l}\text { Moradias afetadas por } \\
\text { enxurradas porque } \\
\text { a rede pluvial é } \\
\text { insuficiente, havendo o } \\
\text { risco de alagamento em } \\
\text { razão da proximidade } \\
\text { do ribeirão. }\end{array}$ \\
\hline
\end{tabular}




\begin{tabular}{|c|c|c|c|c|c|c|c|}
\hline \multirow[b]{2}{*}{ Setor } & \multirow[b]{2}{*}{ Delimitação } & \multirow{2}{*}{$\begin{array}{l}\text { Ameaças e } \\
\text { Riscos }\end{array}$} & \multirow{2}{*}{$\begin{array}{c}\text { Grau } \\
\text { de } \\
\text { Risco }\end{array}$} & \multirow{2}{*}{$\begin{array}{c}\mathrm{N} \text {. de } \\
\text { moradias }\end{array}$} & \multicolumn{2}{|c|}{ N. de pessoas } & \multirow[b]{2}{*}{ Observações } \\
\hline & & & & & Adultos & Crianças & \\
\hline $\begin{array}{l}\text { Vila Santa } \\
\text { Helena }\end{array}$ & $\begin{array}{l}\text { Nas margens } \\
\text { do ribeirão } \\
\text { Anicuns, } \\
\text { acima da } \\
\text { Dermu- } \\
\text { Compav. }\end{array}$ & $\begin{array}{l}\text { Enxurradas ou } \\
\text { Inundações } \\
\text { Bruscas e } \\
\text { Alagamentos }\end{array}$ & Baixo & 6 & 17 & 5 & $\begin{array}{l}\text { Apesar de ter sido } \\
\text { construída uma } \\
\text { passagem para as } \\
\text { enxurradas, quando o } \\
\text { córrego está cheio a } \\
\text { comporta apresenta } \\
\text { problemas. }\end{array}$ \\
\hline Celina Park & $\begin{array}{l}\text { Nas margens } \\
\text { do córrego } \\
\text { Macambira }\end{array}$ & Erosão Fluvial & Médio & 3 & 21 & 6 & $\begin{array}{l}\text { Desbarrancamento } \\
\text { causado por } \\
\text { precipitação hídrica, } \\
\text { podendo atingir } \\
\text { moradias próximas às } \\
\text { margens. }\end{array}$ \\
\hline Vila Roriz & $\begin{array}{l}\text { As margens } \\
\text { do rio meio } \\
\text { ponte na } \\
\text { confluência } \\
\text { com ribeirão } \\
\text { Anicuns }\end{array}$ & $\begin{array}{l}\text { Enxurradas ou } \\
\text { Inundações } \\
\text { Bruscas } \\
\text { e Alagamentos }\end{array}$ & Médio & $\begin{array}{c}\text { Não } \\
\text { cadastrado }\end{array}$ & $\begin{array}{c}\text { Não } \\
\text { cadastrado }\end{array}$ & $\begin{array}{c}\text { Não } \\
\text { cadastrado }\end{array}$ & $\begin{array}{l}\text { Edificações construídas } \\
\text { dentro da cota de } \\
\text { alagamento do rio meia } \\
\text { ponte. }\end{array}$ \\
\hline
\end{tabular}

Fonte: Elaboração da autora com base em dados da Defesa Civil (2008).

Ainda sobre as áreas de risco em Goiânia, assim denominadas pela Defesa Civil e aqui entendidas como áreas de ocorrência de acidentes, a Tabela 3 mostra: (1) as áreas consideradas de risco em Goiânia em 2004; (2) as áreas que continuaram a ser consideradas de risco em 2007; (3) as que deixaram de ser consideradas de risco; e (4) as que não eram consideradas e passaram a ser.

Além disso, a Tabela 3 identifica qual é o tipo de risco considerado para cada localidade. Com base nessa tabela, puderam ser identificados os locais onde os acidentes são recorrentes. Aparecem ao todo, nessa comparação entre as duas datas, 26 bairros onde ocorrem acidentes relacionados à dinâmica fluvial no período de 2004 a 2007. Esse fato explica a diferença entre os números que aparecem nos dados da Defesa Civil e nos inventariados a partir das notícias de jornais. A Defesa Civil atualiza seus dados periodicamente, retirando aqueles que não apresentam mais riscos iminentes. O inventário, por sua vez, apresenta todas as ocorrências entre os anos de 2004 e 2007 que foram noticiadas nos jornais.

Entre os locais onde permanece a possibilidade de riscos, vê-se que os bairros localizados às margens do rio Meia Ponte, como o Monticelli; os localizados nas bacias mais ocupadas da porção sul de Goiânia, com ênfase no Jardim América, na bacia do córrego Cascavel, e no Jardim Guana- 
bara II, edificado sobre a bacia do córrego Pedreira, aparecem em ambos os anos, o que denota que os acidentes que ocorreram nesses bairros não são eventos isolados.

Tabela 3 - Áreas de risco delimitadas pela Defesa Civil em 2004 e 2007.

\begin{tabular}{l|c|c|l}
\hline Áreas de risco & 2004 & 2007 & Qual o risco? \\
\hline Coronel Cosme & $\mathrm{X}$ & & Inundação e alagamento \\
\hline Jardim das Aroeiras & $\mathrm{X}$ & & Erosão (desabamento e deslizamento) \\
\hline Emílio Póvoa & $\mathrm{X}$ & $\mathrm{X}$ & Movimentos de massa \\
\hline Vila Nossa Senhora Aparecida & $\mathrm{X}$ & $\mathrm{X}$ & Inundações e alagamento \\
\hline Vila São Paulo & $\mathrm{X}$ & $\mathrm{X}$ & Inundação e alagamento \\
\hline Vila Santa Helena & $\mathrm{X}$ & $\mathrm{X}$ & Inundação e alagamento \\
\hline Água Branca & $\mathrm{X}$ & & Movimento de massa (fluvial) \\
\hline Monticelli & $\mathrm{X}$ & $\mathrm{X}$ & Inundação \\
\hline Vila Santa Efigênia & $\mathrm{X}$ & & Movimento de massa (fluvial) \\
\hline Setor Sudoeste & $\mathrm{X}$ & & Inundação e deslizamento \\
\hline Vila Fernandes & $\mathrm{X}$ & $\mathrm{X}$ & Inundação e alagamento \\
\hline Jardim América & $\mathrm{X}$ & $\mathrm{X}$ & Movimento de massa (fluvial) \\
\hline Vila Isabel & $\mathrm{X}$ & & Movimento de massa (fluvial) \\
\hline Urias Magalhães & $\mathrm{X}$ & & Inundação e alagamento \\
\hline Vila Roriz & $\mathrm{X}$ & & Inundação e alagamento \\
\hline Vila Ana Maria & $\mathrm{X}$ & $\mathrm{X}$ & Inundação \\
\hline Jardim Guanabara II & $\mathrm{X}$ & $\mathrm{X}$ & Inundação \\
\hline Divisa do Celina Park com o Jardim Europa & & $\mathrm{X}$ & Erosão fluvial \\
\hline Proximidades do córrego Vaca Brava, na & & $\mathrm{X}$ & Inundação \\
\hline Avenida T-9 & & & \\
\hline Jardim Goiás (Vila Lobó) & & $\mathrm{X}$ & Alagamento \\
\hline Campinas & & $\mathrm{X}$ & Alagamento \\
\hline Jardim América & & $\mathrm{X}$ & Alagamento \\
\hline Setor Marista & & $\mathrm{X}$ & Alagamento \\
\hline Conjunto residencial João Braz II & & $\mathrm{X}$ & Alagamento \\
\hline Bairro São Franscisco & & Alagamento \\
\hline Conjunto Rodoviário & & \\
\hline & & & \\
\hline
\end{tabular}

Fonte: Defesa Civil (2008).

O número total de moradias em áreas de risco (2007) e de adultos e crianças que vivem nessas áreas em Goiânia é apresentado na Tabela 4. Esse número foi disponibilizado pela Defesa Civil e complementa os dados da Tabela 2. Um fato preocupante mostrado nessa tabela é que praticamente um terço dos moradores de áreas de risco são crianças que, em 
razão de sua vulnerabilidade, em eventos relacionados à inundação, são muito suscetíveis a acidentes.

Tabela 4 - Famílias em área de risco em 2006 - Goiânia.

\begin{tabular}{c|c|c}
\hline Número de moradias & Números de Adultos & Número de crianças \\
\hline 645 & 1240 & 651 \\
\hline
\end{tabular}

Fonte: Defesa Civil (2008).

A Tabela 5 apresenta todos os locais onde foram identificados acidentes relacionados a alagamentos e principalmente inundações em Goiânia, bem como as suas coordenadas planas e os cursos d'água ao qual cada ponto está relacionado para o caso de inundação. Essa tabela apresenta a localização geográfica dos pontos de ocorrência de acidentes, que foram identificados no Siggo (SAD69) e Google Earth (WGS84), a partir dos endereços e pontos de referência obtidos nos dados levantados ao longo do trabalho e mostrados nas tabelas anteriores. Nesses softwares buscou-se, a partir do endereço, encontrar as coordenadas (projeção UTM, Datum SAD69, Meridiano Central 51 ${ }^{\circ} \mathrm{W}$ Gr.) da localização de cada ponto onde foram identificados eventos de inundações.

Para que se possa ter o cenário da distribuição dos acidentes fluviais em Goiânia, os pontos de inundação foram espacializados e foi elaborado um mapa a partir do que foi compilado e apresentado nessa tabela.

Tabela 5 - Localização das inundações em Goiânia.

\begin{tabular}{c|l|c|c|c}
\hline ID & Localização & Y & X & Curso d'água \\
\hline 1 & Parque Amazônia (Av. Feira de Santana) & 684265 & 8149799 & Serrinha \\
\hline 2 & Avenida Rio Verde (Entre Goiânia e Aparecida) & 678091 & 8147401 & - \\
\hline 3 & $\begin{array}{l}\text { Jardim da Luz próximo ao Buriti Shopping (Av. Maria } \\
\text { Cardoso) }\end{array}$ & 688417 & 8150090 & Barreiro \\
\hline 4 & Vila Alzira (Av. das Mangueiras) & 689135 & 8144977 & Santo Antonio \\
\hline 5 & Bairro Goyá (Rua da Alegria) & 678990 & 8154551 & Macambira \\
\hline 6 & Conjunto Caiçara (BR-153) & 690427 & 8157712 & Meia Ponte \\
\hline 7 & Vila Santa Rita & 678861 & 8155319 & Anicuns \\
\hline 8 & $\begin{array}{l}\text { Vila Coronel Cosme (Entre a Rua da Paz e o Meia Ponte) } \\
\text { abaixo da via férrea }\end{array}$ & - & - & - \\
\hline 9 & Vila Maria Rosa (João Leite) & 688264 & 8162350 & João Leite \\
\hline
\end{tabular}




\begin{tabular}{|c|c|c|c|c|}
\hline ID & Localização & $\mathbf{Y}$ & $\mathbf{x}$ & Curso d'água \\
\hline 10 & Bairro Emílio Póvoa (João Leite) & & & \\
\hline 11 & $\begin{array}{l}\text { Bairro Emílio Póvoa (Al. Botafogo entre a Av. 1, Vila } \\
\text { Nova e R. Dr. Constantino Gomes no Crimeia Leste) }\end{array}$ & - & - & - \\
\hline 12 & Vila Roriz (Rua Cloves Roberto Espelin) & 685186 & 8159538 & Meia Ponte \\
\hline 13 & Jardim Guanabara II (Rua GB26 e GB27) & 690531 & 8163141 & Pedreira \\
\hline 14 & Vila Monticelli (Fundo da Saneago, meia ponte) & 686634 & 8158664 & Meia Ponte \\
\hline 15 & Recanto do Bosque & 681491 & 8163786 & Meia Ponte \\
\hline 16 & Jardim Goiás (Vila Lobó) & 687346 & 8153683 & Botafogo \\
\hline 17 & $\begin{array}{l}\text { Celina Park (Macambira) Av. Milão, Jardim Europa/ } \\
\text { Celina Park }\end{array}$ & 679353 & 8151890 & Macambira \\
\hline 18 & Jardim Novo Mundo & 691555 & 8156991 & Meia Ponte \\
\hline 19 & Urias Magalhães (Av. Pampulha, Chácaras n. 2, 4, 5 e 6) & 684908 & 8160123 & Meia Ponte \\
\hline 20 & Setor Jaó & 688448 & 8157546 & Meia Ponte \\
\hline 21 & Jardim América C4/C6 & 682136 & 8153420 & Cascavel \\
\hline 22 & Jardim América Av. Chili, Od. 406A Lt. 1 e 2 & - & - & - \\
\hline 23 & Jardim das Aroeiras (Invasão do Buracão) & 692005 & 8156909 & Meia Ponte \\
\hline 24 & $\begin{array}{l}\text { Vila Nossa Senhora Aparecida (Rua 1, chácaras 1, } 2 \\
\text { e 3) }\end{array}$ & 694213 & 8158495 & Anicuns \\
\hline 25 & $\begin{array}{l}\text { Vila São Paulo (Rua Padre Antão, Chácara 3; Rua } 4 \text { e } 5 \\
\text { Od. 14, 15, } 17 \text { e 18) Anicuns }\end{array}$ & 681855 & 8157650 & Cascavel \\
\hline 26 & $\begin{array}{l}\text { Vila Santa Helena (Nas margens do Anicuns, acima do } \\
\text { Dernu-compav) }\end{array}$ & 683550 & 8158332 & Anicuns \\
\hline 27 & Água Branca (nascente do córrego Água Branca) & 689652 & 8153377 & Água Branca \\
\hline 28 & $\begin{array}{l}\text { Vila Santa Efigênia (margens do Vaca Brava, Av. C-6, Od } \\
\text { 44, em frente à Santa Casa) }\end{array}$ & 682142 & 8153849 & $\begin{array}{l}\text { Cascavel/vaca } \\
\text { Brava }\end{array}$ \\
\hline 29 & Setor Sudoeste & 682186 & 8154145 & Cascavel \\
\hline 30 & $\begin{array}{l}\text { Vila Fernandes (Rua 30, Od. 1, 2, } 3 \text { Lt. } 1 \text { ao 8, } 10 \text { e } 12 \\
\text { (Anicuns) }\end{array}$ & 684048 & 8158435 & Anicuns \\
\hline 31 & Vila Isabel (lado direito, na baixada da Segunda Radial) & 687197 & 8151413 & Botafogo \\
\hline 32 & Vila Ana Maria & - & - & - \\
\hline 33 & Av. T9, próximo ao Vaca Brava & 683847 & 8152326 & Vaca Brava \\
\hline 34 & Campinas & 681621 & 8156222 & Cascavel \\
\hline 35 & Setor Marista & 685736 & 8152085 & Areião \\
\hline 36 & Conjunto Residencial João Braz II & 675086 & 8155033 & Anicuns/Salinas \\
\hline 37 & Bairro São Francisco & 679454 & 8156222 & Anicuns \\
\hline 38 & Conjunto Rodoviário & 681324 & 8155795 & $\begin{array}{l}\text { Cascavel } \\
\text { (tributário) }\end{array}$ \\
\hline
\end{tabular}

Fonte: Elaborado pela autora. 
Observa-se no mapa elaborado com bae na Figura 1 uma concentração dos acidentes na porção centro-sul do município. Essa concentração coincide com a região mais urbanizada da capital. Isso acontece porque a bacia do ribeirão Anicuns, onde se encontra edificada a maior parte de Goiânia, foi a área destinada à construção da capital. O Decreto n. 3359, de 18 de maio de 1933, determinou que a região às margens do córrego Botafogo, compreendida pelas fazendas denominadas Crimeia, Vaca Brava e Botafogo, no então município de Campinas, fosse escolhida para nela

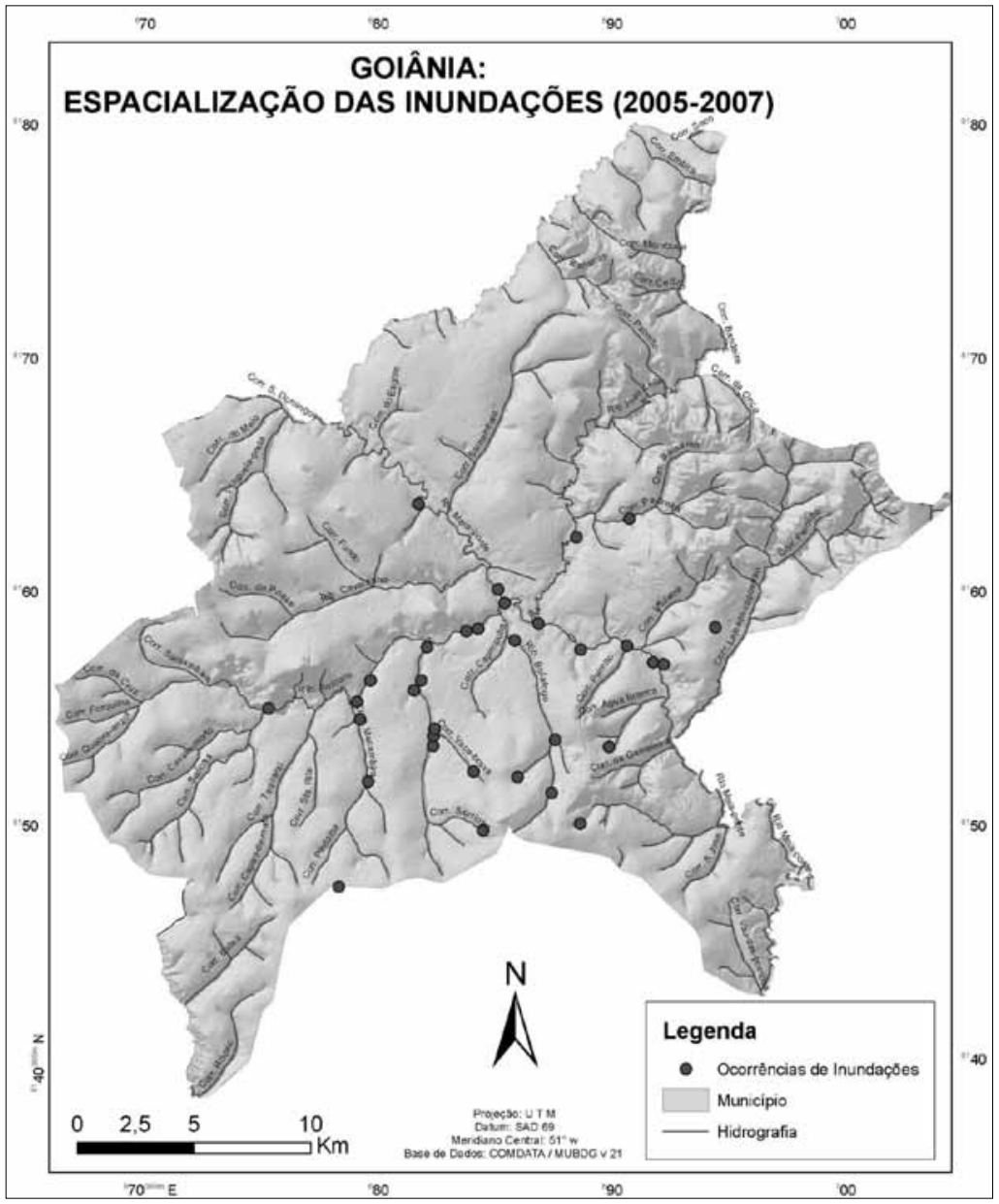

Figura 1 - Espacialização das inundações em Goiânia, com base em dados de 2004 a 2007. 
ser edificada a nova capital do estado (IBGE, 2009). Tendo sido o marco inicial da implantação de Goiânia, essa região se tornou hoje a mais densamente povoada e com grandes taxas de ocupação e consequente impermeabilização do solo.

Assim, em Goiânia destacam-se as bacias da porção sul da cidade, que apresentam altos níveis de ocupação e ocorrência de eventos de inundação associados aos córregos Macambira, Cascavel e Botafogo. Essas bacias apresentam vários pontos de ocorrência de eventos de inundação, o que pode ser observado na Figura 2 e na Figura 3, onde os números mostram que a quantidade de locais de ocorrência de inundações nessas bacias assemelha-se aos que estão associados à de cursos d'água maiores, como o rio Meia Ponte.

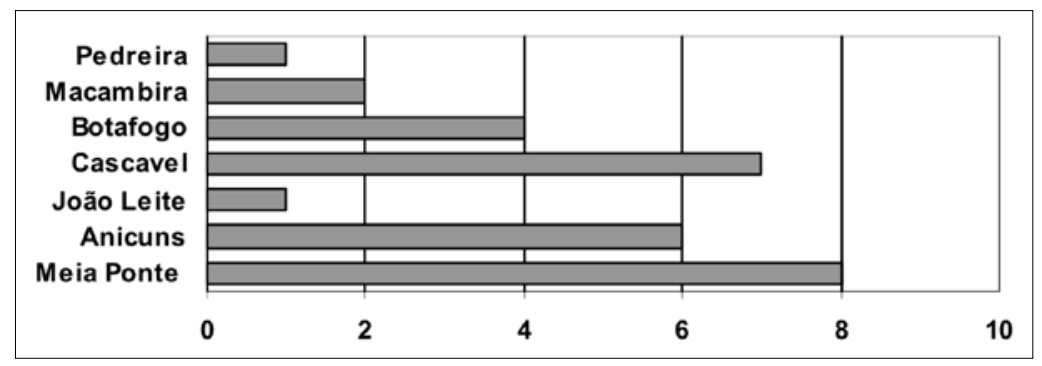

Figura 2 - Número de locais com registros de inundações por bacias hidrográficas em Goiânia.

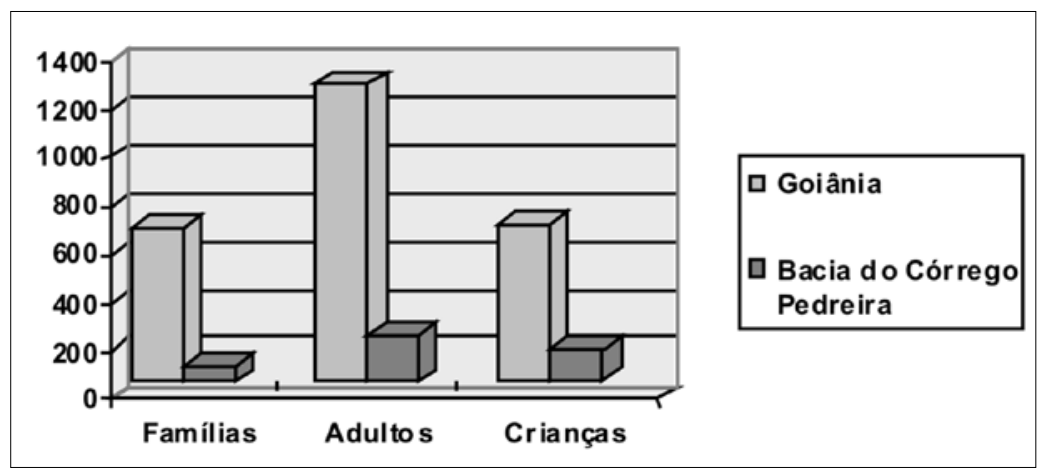

Figura 3 - Pessoas em área de risco em Goiânia e na bacia do córrego Pedreira, 2006. 
Essas bacias apresentam grande impacto decorrente da urbanização e das modificações empreendidas no sistema de drenagem urbana, bem como das intervenções no leito do rio. A comparação entre mosaicos de fotografias aéreas de 1989 e de 2006, juntamente com a análise da rede de drenagem desses períodos, demonstrou que os canais de drenagem de dois dos afluentes do ribeirão Anicuns foram amplamente modificados através de retificação, canalização e construção de marginais, sendo estes os córregos Cascavel e Botafogo. Os demais pontos estão associados ao Anicuns, Meia Ponte e ao João Leite em menores proporções. Além desses locais, aparecem os córregos Pedreira e Água Branca e alguns pontos considerados como alagamentos, por não estarem associados a cursos d'água.

Com base nessa breve análise, pode-se compreender a grande concentração de eventos de inundação na porção sul de Goiânia que se apresenta amplamente urbanizada, impermeabilizada e com a rede de drenagem modificada. A bacia do córrego Pedreira, porém, não apresenta características semelhantes às das bacias da porção sul de Goiânia, já que é usada inclusive por propriedades rurais. Tampouco apresenta as proporções de um rio ou ribeirão. No entanto, destacou-se ao longo da análise dos dados desse trabalho pela frequência de acidentes.

Apesar de aparecer com apenas um local de ocorrência de inundação com danos a seres humanos e ter sido classificada como nível médio de risco pela Defesa Civil (2008), a bacia do córrego Pedreira tem apresentado eventos de acidentes recorrentes ano após ano. Além disso, o número de famílias ali instaladas é relevante, se comparado ao número apresentado para Goiânia. Apesar de algumas famílias terem sido removidas pela Prefeitura, muitas ainda ocupam a área onde ocorrem os acidentes.

Segundo dados da Defesa Civil (2008) descritos anteriormente, existem em Goiânia 645 famílias morando em áreas de risco em Goiânia. Mais de 10\% dessas famílias residem na bacia do córrego Pedreira (Figura 3). Das 69 famílias que moram em áreas de risco nessa bacia, 201 são adultos e 137 são crianças.

A ocorrência de vários acidentes e a sua continuidade temporal denota que a probabilidade de haver inundações nos próximos períodos chuvosos é grande. Com a população ainda habitando em áreas impróprias, esse risco se intensifica. 


\section{Considerações finais}

As inundações trazem consequências danosas principalmente para as populações ribeirinhas. A ocupação das áreas marginais dos rios prejudica primeiramente a parcela da população que se instalou no leito do rio. Porém, ao se instalar nas áreas naturalmente inundáveis, essa mesma população que sofre com esse fenômeno passa a contribuir para que as consequências se estendam a um número ainda maior de pessoas.

Nas notícias sobre esses fenômenos veiculadas em jornais da cidade são relatadas as consequências, compreendendo transtornos no trânsito com pontes interditadas, desvio do tráfego e engarrafamentos. Prejuízos materiais incluem destruição de móveis, alimentos e eletrodomésticos em casas inundadas e/ou alagadas e danos em carros cujos motoristas arriscaram a travessia. Danos sociais incluem desconforto, revolta e medo da população atingida. Outros danos provocados pelas inundações podem incluir a ocorrência de doenças como leptospirose e disenteria, entre outras.

\section{Referências}

COMDATA - Cia. de Processamento de Dados do Município de Goiânia. Mapa Urbano Básico Digital de Goiânia (MUBDG). CD-ROM Profissional Versão 20 - Parte integrante do SIGGO V13. Goiânia: Prefeitura de Goiânia, 2007.

DEFESA CIVIL. Risco de desastres relacionado com incremento de precipitações hídricas e com as inundações. Relatório Técnico. Goiânia, 2008.

IBGE. Banco de Dados Agregados. Sistema IBGE de Recuperação Automática (SIDRA). Disponível em: <http://www.ibge.gov.br>. Acesso em: 16 jan. 2009.

SOUZA, C. R. de G. Cartografia de risco à inundação no litoral paulista: o exemplo do município de São Sebastião. São Paulo: USP/Unesp, 1996.

TUCCI, C. E. M. Drenagem Urbana e Controle de Inundações. In: CAMPOS, Heraldo \& CHASSOT, Attico (Org.). Ciências da terra e meio ambiente. São Leopoldo: Ed. Unisinos, 1999.

TUCCI, C.E.M. Águas Urbanas. In: TUCCI, C. E. M; BERTON, J. C. (Org.). Inundações urbanas na América do Sul. Porto Alegre: Associação Brasileira de Recursos Hídricos, 2003a.

TUCCI, C.E.M. Inundações e Drenagem Urbana. In: TUCCI, C. E. M; BERTON, J.C. (Org.). Inundações urbanas na América do Sul. Porto Alegre: Associação Brasileira de Recursos Hídricos, 2003b. 
Kesia Rodrigues dos Santos - Possui graduação em geografia pela Universidade Estadual de Goiás. Atualmente é mestranda em geografia pela Universidade Federal de Goiás.

Patrícia de Araújo Romão - Possui graduação em geologia pela Universidade de Brasília (1991), mestrado e doutorado em geotecnia pela Universidade de Brasília (1995 e 2006, respectivamente). Atualmente é Professora Adjunto II da Universidade Federal de Goiás.

Recebido para publicação em maio de 2010 Aceito para publicação em setembro de 2010 